\title{
HOW TO FRAME EDIBLE ART
}

\section{Adam Andrzejewski}

\begin{abstract}
The question of whether food is art depends primarily on the definition of art that we agree to accept. The article proposes a model that helps us to focus our mind on what could be, and how we should understand the art of food, if we accept, having applied a fairly liberal theory of art, that food can actually be art. It is argued that there are no methodological or factual constraints indicating that food could not, under some circumstances, be high art. This hypothetical form of art is called 'edible art'.
\end{abstract}

\section{KEYWORDS}

Food Aesthetics, Gustatory Experience, Taste, Art Form, Food Art, Aesthetic Appreciation, High Art

\section{INTRODUCTION}

A debate has been continuing in philosophical aesthetics about whether or not food can be art. If the answer is affirmative, then the problem, at least to some extent, concerns classification: what kind of art is food? Culinary dishes can be regarded as entities similar to flower arrangements, design, or decoration, which makes them works of minor art. On the other hand, they can be seen as entities similar to, for example, sculpture and thus regarded as works of high art. In their pioneering research into the philosophy of food, Elisabeth Telfer and Carolyn Korsmeyer both prefer the first option: food belongs with works of minor art.

According to Telfer there are three reasons for considering food as minor art. ${ }^{1}$ First, food is transient. This is so because dishes often exist for no more than a few hours and are demolished during consumption. Thus, we can contemplate them for a short time only. Second, food does not have any significant meaning, in particular the kind of meaning that we attach to performing arts. Food refers us back to ourselves but does not tell us much "about the world and ourselves." 2 Third, food does not stir in us the kind of emotions that literature or music do. According to Telfer, it is rather hard to imagine food affecting us to the same extent as, for example, the experience of watching a play in a theatre. 
Korsmeyer delves deeper in her exploration of the artistic aspects of food since she claims that food does have meaning. ${ }^{3}$ However, she points out a further three constraints thanks to which food cannot enjoy the status of high art. ${ }^{4}$ First, the meaning of food is strongly context based. Food is often connected with some strong narrative-cultural or personal-that imparts symbolic and aesthetic meaning to it. This suggests that it is not the food itself that has meaning but the context within which it is set. Second, food does not excite 'reflection and attention' to the same extent as art does. The use of food as an element of a ritual or social practice makes us reflect more on the ceremony itself. As such, it is not a sign of its inner greatness; "food as food." 5 In other words, food rarely (if ever) compels us to a reflection on food. Usually, it refers to some larger context (e.g., dishes traditionally associated with a religious holiday). ${ }^{6}$ Third, the aesthetic qualities of food stem from its utilitarian nature. According to Korsmeyer, the idea of art for art's sake, where art does not seek its justification beyond itself, still holds sway. To sum up, both Telfer and Korsmeyer believe that food can constitute works of art, but these are only minor art. The distinction is justified because food is beset with all kinds of constraints, stemming from its physical and cultural properties, from which objects of high art are largely free.

In this paper, however, I try to make room for another option. That is, the possibility for food to constitute works of high art. There is no doubt that the question of whether food is art depends primarily on the definition of art that we agree to accept as art. In other words, $x$ is a work of art by reference to definition $\alpha$ if and only if $x$ satisfies $\mathrm{F}$, where $\mathrm{F}$ is a set of conditions both necessary and sufficient for anything to be regarded as a work of art within the meaning of $\alpha$. It is worth noting too that even if the definition of art and the concept of a form of art are closely related, they are conceptually independent of each other. It is instructive that many incompatible theories of art (e.g., formalism, institutional theory, functionalism) accept (relatively) the same concept of the form of art (e.g., painting or music). Thus, this paper does not seek to provide direct answers to whether food is art or not. Rather, I have set out to propose a model that helps us to focus our mind on what could be, and how we should understand, the art of food, if we accept that food can actually be art. I have chosen the label 'edible art' for this (hypothetical) form of art. I claim as well that if we accept that food can be art, there are no methodological or factual constraints indicating that food could not, under some circumstances, be high art. I believe that I could make my claim without committing myself 
to any particular definition of art. However, I do need agreement at some points on what art is, but I hope these are quite uncontroversial. For example, artworks usually express aesthetic properties, trigger a certain kind of reflection, have a meaning, etc. All these things are precisely the kinds of claims people make in isolating what is interesting and important about artworks. And, as I shall argue, it can also be said about some culinary dishes. The sense in which I use the term 'art' is a descriptive and classificatory one.

The paper is structured as follows. $\S 2$ discusses the ways in which food can be art and sets out conditions that a culinary dish must satisfy to be perceived as an example of high art. Next, in $\S$ 3 , I discuss the main assumptions and examples of 'revolutionary cooking', which is a trend in contemporary gastronomy. Finally, § 4 traces the analogy between revolutionary cooking and conceptual art. This analogy is intended to deepen the understanding of revolutionary cooking and its relationship with existing trends in art. In this way, I attempt to show that revolutionary cooking dishes can be regarded as a form of art, of which 'edible art' is an example. A summary of my argument follows in $\S 5$.

\section{THE ART FORM QUESTION}

The first task in discussing the artistic status of food is to determine what forms of art culinary dishes can exemplify. I have briefly outlined Telfer's and Korsmeyer's positions, both holding that food is a 'minor' or 'applied' art, which contrasts with 'high' or 'fine' art such as literature or music. It seems that the two researchers treat the distinction between high and minor art as related to the art forms. That is, some art forms are exclusively high art, whereas others are minor art. In this paper I shall argue that food might be treated as an art form of bilateral design which means that it has both high and low manifestations. ${ }^{7}$ I show that some instances of food do not have the constraints of 'minor' art as presented by Telfer and Korsmeyer. ${ }^{8}$ Here, I seek to explain the considerations necessary to understand any potential forms of art to which food might give rise. I do not deny that there are some definitions of art that would have no trouble including food in (fine) art. Such definitions might be taken, for example, from the aesthetic proposals by Nick Zangwill (Aesthetic Creation, Oxford: Clarendon Press, 2007) or Gary Iseminger (The Aesthetic Funtion of Art, Ithaca: Cornell University Press, 2004). However, in this essay I am not concerned directly with the definitional reasons that ground the inclusion of food in art. This is a matter of a particular definition of art we are committed to. In other words, we may accept-following Zangwill's 
or Iseminger's view-that food is art and thus, we still need to define how we should understand, experience, and appreciate the art of food (and not just merely categorise it as belonging to the art world).

Let us assume that every work of art is created to convey a certain content. ${ }^{9}$ This content is conveyed by the medium that was used to create the work of art. The conventional distinction has it that there is a physical medium and an artistic medium. ${ }^{10}$ The physical medium is the material that is needed to create the work. For example, a sonnet consists of word tokens, whereas a neo-Gothic cathedral consists of bricks. By contrast, the artistic medium is a set of conventions that determine the way in which the physical medium is distributed; e.g. a certain arrangement of words that helps us to decide whether an 'entity' is a sonnet or a piece of prose. The artistic medium then sets the parameters necessary for experiencing and judging a work in a certain way. For example, in dancing, we will be looking at the steps and the intervals between them. Such parameters help us to distinguish dancing from walking or running. These two types of media are related in the following way: the artistic medium is embodied in the physical medium, or, put another way, the physical medium is the vehicle for the artistic medium. ${ }^{11}$ All works of art are characterized by these two types of media.

As regards the form of art, I take it to be the kind that encompasses all works of art using the same artistic medium. In other words, all works of art that share the same medium for the distribution of the physical medium belong to the same form of art.12 The form of art also plays an explanatory role to some extent. Its properties explain why a certain artistic medium was used in the production of a work of art rather than another. ${ }^{13}$ Bearing the above in mind, I propose a distinction between three different ways in which food can be art.

First, food is a medium used for other forms of art. Examples include the gigantic sculpture A Subtlety (2014) by Kara Walker, made entirely out of sugar, or the portrait of Kevin Bacon (2010) by Jason Macier, made from fried bacon. Thus, when we say that food is art, what we actually mean is that it is art when it belongs to another form of art, here sculpture or painting, respectively. The reason is that the message contained in these works is conveyed through a common artistic medium (i.e., the conventions of sculpture and of painting).

Second, food is not only a physical medium but also an artistic one. As far as I know, no one has yet taken this perspective in analysing food, so I propose that the artistic medium in the case 
of food should be thought of as the conventions and methods used in preparing culinary dishes. The conventions select the physical medium-ingredients-for producing dishes and the methods are ways in which food is prepared as well as ways in which flavours are combined. (I unpack some of these in $\S 4$ ). If so, food is a form of art. Such art is experienced primarily through taste and smell. ${ }^{14}$ Where we judge a culinary dish only with our eyes, the most that we can do is to expound on its visual appeal. We do not learn anything about its essential properties: how it tastes. Hence, we have no information about how its artistic medium was used.

Thinking about art in this way can result in theoretical tension. On the one hand, we appreciate the value of food, regarding it as a form of art. On the other hand, the rehabilitated aesthetic and artistic dimension of food turns out to be dependent on something that is extrinsic to food itself. Korsmeyer says: "The symbolic function of food of wider variety,” being a guarantee of its artistic dimension, "those that involve expression and denotation in particular-seem to require a place in some cultural practice in order to come into being." 15 Later she writes: "[u]nlike music or other fine art, however, this sort of reflection - important as it is - is not a mark of greatness for food as food." 16 Such art, according to Korsmeyer, is somewhat 'incomplete', because its artistic dimension depends on something other than itself. This is precisely what distinguishes food from other art forms and determines that if food is indeed art, it is only a minor art. ${ }^{17}$ This seems to be another line of establishing the distinction between high and minor art. Artistic dimension of the former does not depend on something other than itself.

I have no doubt that Telfer's and Korsmeyer's conceptions can be applied to most culinary dishes. Food can sometimes be the material for other works of art, and in cases where this fits, the theory of art and the culinary conventions are used as an artistic medium, the same dishes can be their own separate artworks. I also agree that the lion's share of such artworks come up against the constraints referred to by Telfer and Korsmeyer. Where I take issue with them is the claim that those constraints are insurmountable.

Thus, I should like to propose a model whereby food could be regarded as high art (as understood by Telfer and Korsmeyer). I shall call this form of art 'edible art'. As I have said before, the proposition that some object $x$ is a work of art is taken to mean that $x$ satisfies the necessary and sufficient conditions of being art under art theory $\alpha$. Let us assume that for food to be a work of art, each object-i.e. each culinary dish $x$ falling within edible artmeets the following conditions jointly: 
Edible art: (i) $x$ satisfies $\mathrm{F}$, where $\mathrm{F}$ is a set of conditions both necessary and sufficient for anything to be regarded as a work of art within the meaning of $\alpha$, (ii) $x$ satisfies $F$ due to the fact that $X$ is eaten, experienced and judged primarily as food.

I call (ii) the Autonomy Condition. In other words, I claim that culinary dishes, construed in this way, are examples of art by virtue of art theory $\alpha$ and they manifest their artistically relevant properties through being eaten, experienced, and judged as food. These are the necessary parameters for the understanding, experience, and critical evaluation of edible art.18 It is important to stress that the term 'eating' here is understood as the multisensory process of food consumption. ${ }^{19}$ When eating a dish all the senses are involvedwith the dominance of taste-and they influence each other. That is, by manipulation of, for example, the visual or olfactory aspects of the dish we might end up with different gustatory experiences. ${ }^{20}$

Culinary dishes as an example of edible art cannot derive their status from something that is extrinsic to them but must derive it from attributes that are inherent in them. Put another way, if some of their qualities need an artistic or aesthetic enhancement, they are precisely the qualities that stem from the fact that the examples of this kind of art are culinary dishes. Moreover, perceiving those qualities in terms of the culinary framework is the most appropriate way of experiencing them. ${ }^{21}$ To turn Korsmeyer's words on their head, we could say that we are dealing here with examples of such a kind of art as would lead us to focus and reflect precisely on the fact that they are food.22 In my view, if we admit that edible art is a form of art, we will be able to understand a whole range of interesting developments taking place in modern culinary practice. I mean, in particular, the so-called revolutionary cooking.

\section{REVOLUTIONARY COOKING: IDEAS AND PRACTICES}

It is helpful perhaps to explain first what revolutionary cooking is and to give some examples. Revolutionary cooking is a trend on the contemporary cooking scene that is characterized by, among other things, self-awareness as a symbolic form, emphasis on the receptive moment as a continuation of the creative process, appropriation of certain components of artistic, scientific, and technological research. Revolutionary cooking is also marked by development of mutual influences between creativity and research, and involvement in the narrative of its own history and creative process. ${ }^{23}$

The term 'revolutionary cooking' was coined with a view to differentiating certain trends in modern gastronomy from 
developments commonly referred to as molecular gastronomy, which is a branch of science studying the physical and chemical transformations of food ingredients during cooking. ${ }^{24}$ This is not to say that revolutionary cooking does not avail itself of solutions developed by molecular gastronomy. The relationship is best appreciated once we recognise the two fundamental approaches to cooking: the traditional and the creative. ${ }^{25}$ The former is based on culinary knowledge passed down from generation to generation and on detailed recipes. This approach is characterised by a certain kind of regularity, tradition or a fixed canon regarding the making of some dishes. The latter approach seeks to challenge accepted norms and to explore new taste combinations and new cooking technologies. The creative approach is characterised by a high level of innovation in which the cook's creativity is free of traditional bounds, but also by a desire to express certain aesthetic attributes; e.g. beauty or glamour.

The differences that lie at the heart of the division into traditional and creative cooking determine the criteria of assessment of dishes in either of the two categories. In the traditional approach, the consumer orders a particular dish and expects it to be made just as she has imagined it. Fulfilment or otherwise of her expectations directly determines how a dish is judged. The creative approach dispenses with a definitive account of the stilted tropes of traditional cooking. Besides being able to appreciate the taste, flavour, or texture of the food that she has ordered, the consumer should also be able to note such things as innovation, creativity, or the element of surprise. By putting aside sanctioned rules, creative cooking is more open to scientific discoveries than traditional cooking. Creating new tastes or choosing new, often shocking, forms for familiar dishes calls for the use of complicated techniques and knowledge from the fringes of physics and chemistry. ${ }^{26}$

I will now briefly describe three revolutionary cooking dishes. They were all created by Ferran Adrià and served in his el Bulli restaurant. The first such dish is Margarita (2005). It takes the shape of a snow-white cube with a dab of salty foam on top. The food is eaten with a teaspoon. Its shape and consistency cheat our intuitions about the margarita drink: an alcoholic beverage must necessarily be a liquid. Imbibing this 'drink' makes for an even more perplexing experience given the fact that it is served as an aperitif. We cannot regard it as 'margarita-flavoured ice cream', as Margarita was served with olives (Olivas Sféricas, 2005). At first glance, the olives resemble the familiar fruit such as nature might have produced. Inside the mouth though, the fruit bursts and spills 
an oily, green olive-flavoured liquid. Fake olives challenge one of the dearly held myths of modern gastronomy: that gastronomy should use only the freshest and most natural, i.e. unprocessed, ingredients: the more natural the product, the better. In that case, nothing could be further from the truth. Guests agreed that Adrià's fake olives tasted better than the real ones.

Another interesting dish is an olive oil spring (Muelle de aceite de oliva virgin, 2005) that sits on large salt crystals. One should put it on one's finger and slowly eat the 'coils', which produces the sensation of the spring melting in the mouth. The dish was served in a minimalist black box that looked unmistakably like a jewel box. This may be a deft allusion to Spain's national treasures: salt and olive oil.

\section{REVOLUTIONARY COOKING AS EDIBLE ART}

I shall now endeavour to explain how revolutionary cooking could be understood and experienced as edible art within the model that I have presented in $\S 3$. To this end, it is helpful to recall first the analogy that, in my view, obtains between conceptual art and revolutionary cooking. I do not argue that culinary dishes are works of conceptual art. I believe, however, that the two are related in a non-trivial way; i.e. the relationship between revolutionary cooking and traditional gastronomy works along very similar lines to the relationship between conceptual art and traditional art.

The distinctive feature of conceptual art is the relationship between the idea and the material form of the work. According to Sol LeWitt: "In conceptual art the idea or concept is the most important aspect of the work." 27 One of the key characteristics of conceptual art then is that it proclaims itself to be-says Elisabeth Schellekens-more the art of the mind than the art of objects. ${ }^{28}$ The primacy of idea betrays, above all else, the revisionist (oftentimes the revolutionary) dimension of conceptual art. By using unconventional creation techniques, ready-mades, or promoting the perception of art in a non-institutional setting, conceptual artists challenge the classical claims made about art. In so doing, they provoke a discussion about the role that aesthetics plays in defining art and the nature of the conventional art media, contest the purely formal attributes of objects as sufficient for the classification of an object among the pantheon of works of art, and finally lay bare the commercial practices in the art and cultural artefacts market. ${ }^{29}$ Conceptual art examines the limits that have been imposed on the terms 'art' and 'work of art'. 
Returning to revolutionary cooking, there are many significant differences between revolutionary cooking dishes and conceptual artworks. Nevertheless, there is a certain analogy between revolutionary cooking and conceptual art: revolutionary cooking is characterized by the same sort of relationship to traditional dishes and culinary rules as conceptual art has to conventional art and its rules. ${ }^{30}$ The analogy alone does not justify a claim that revolutionary cooking is art, but it does help us to understand what revolutionary cooking actually is. The analogy can be glimpsed through two aspects: (1) the revisionist, and (2) the revolutionary.

The first aspect involves challenging the basic terms (e.g. 'dish', 'side dish') and debating the conventions of modern gastronomy. This is done through, among other things, deconstruction. ${ }^{31} \mathrm{~A}$ classic recipe is subjected to a number of changes in the course of making the dish, such as change of temperature, the order in which the ingredients are combined, and the method by which they are combined. The result is a dish that has changed beyond recognition (i.e. we are convinced that we have never eaten anything like it before). It is only upon trying it that we can 'reconstruct' its taste because of something called 'culinary memory'. 32 In other words, we recognise the taste of a familiar dish in its deconstructed form and identify it accordingly. The importance of tearing down classical conventions ${ }^{33}$ comes to the fore in el Bulli's cooking manifesto called Synthesis of el Bulli cuisine. One of its postulates proclaims: "The classical structure of dishes is being broken down: a veritable revolution is underway in first courses and desserts, closely bound up with the concept of symbiosis between the sweet and savoury world; in main dishes the 'product-garnish-sauce' hierarchy is being broken down." 34

A dish that captures the revisionist spirit of revolutionary cooking is popcorn (Nube de palomitas, 2005). Popcorn resembles a puffy cloud. The dish itself is interesting for at least two reasons. First, popcorn is not commonly associated with a dish served in fancy restaurants. Its natural habitat is a football ground or a cinema. Popcorn is a prime candidate for el Bulli's two key postulates, decontextualisation of a dish (being yanked out of common associations and placed in a new context) and the claim that each product has the same culinary value (regardless of price). ${ }^{35}$ Second, we are very attached to the way we eat popcorn. Usually, we reach into a good-sized bowl or box, pinch the kernels between our fingers and eat them one by one, relishing their simplicity, warmth and pleasant texture and crunchiness. None of these things has anything to do with popcorn à la Adrià. Rather, 
they motivate us to think of dishes, including even the simplest and most familiar snacks, as not being 'permanently' assigned to their form and context.

I shall focus now on the revolutionary aspect. This aspect is characterised by a gradual change of approach to food and cooking in contemporary culinary trends-those trends that are outside revolutionary cooking. It manifests itself in two main areas of endeavour: (1) concepts and techniques, and (2) conceptualisation and popularisation. ${ }^{36}$

The concepts are dishes that are based on single ideas exploring taste, form, colour, or texture. A classic example of a dish idea is the so-called foams: their material form is reduced to an ephemeral 'cloud'. Techniques are methods of production; e.g. spherification, which involves creating edible balls in a variety of sizes in which taste is 'locked up'. The objects are wrapped in a thin film with no taste of its own. Upon contact with the tongue, the film bursts, and the taste is released. Concepts and techniques are indicators of creativity par excellence, as they, according to Adrià, help to distinguish an ordinary dish from one that is 'evolving'. ${ }^{37}$

Conceptualisation and popularisation are efforts through which information about revolutionary cooking is disseminated to become part of gastronomic usage, popular or academic. One of the mechanisms of conceptualisation at el Bulli involves keeping detailed notes of culinary processes. The notes are in the form of multimedia records of experiments involving new techniques, ingredients, and tastes, and the creation of new recipes and dishes. The records allow the Adrià team to keep track of progress and setbacks over time. The crowning achievements of this process were publication of five el Bulli catalogues containing all its dishes (from 1983 to 2004), including pictures and recipes. This links directly with the other side of el Bulli's strategy: popularisation. In contemporary gastronomy, recipes are easily available online (including pictures of the preparation process, lists of ingredients, and practical tips). This is also reflected in a special line of products that are used in making fine dishes and taste compositions. The line that is endorsed by Ferran Adrià and Albert Adrià is called Texturas. ${ }^{38}$

An example of revolutionary cooking is Caviar sférico de melon. This caviar is made from melon juice using the method of spherification. Such juice 'caviar' tastes deceptively similar to the real fish roe. The dish is Adrià's practical joke at the expense of the consumer and comes in a tin typically used by Iranian caviar producers. 
One of the aims of revolutionary cooking is the transformation of current culinary trends. ${ }^{39}$ The process takes place at a number of levels. The first to be challenged is the theoretical approach to cooking. The approach itself is more and more often seen in terms of categories reserved for art criticism: attention is drawn to creativity, inventiveness, aestheticism, artistry and so on. Moreover, meticulous record keeping facilitates theoretical analysis. The approach used is also a source of valuable information for chefs and for researchers studying gastronomy. 40 The next level where transformation is evident is the change in the preparation of food in the hands of the chefs. New gastronomy promotes new methods and techniques that result in new dishes and new taste experiences.

We can also ask whether the revolutionary cooking dishes meet the Autonomy Condition imposed on our edible art. Recall that under the Autonomy Condition, dish $x$ is eaten, experienced and judged primarily as food. In other words, if there are some aesthetic or artistic qualities inherent in $x$ that should be brought to the fore (imposed by a particular theory of art $\alpha$ and expressed as a set of conditions F), then they stem directly from the fact that $x$ is a culinary dish. To my mind, revolutionary cooking dishes satisfy this condition to a sufficient extent. This is so because of the revolutionary and revisionist nature of such dishes. We can further test this assertion by formulating a counterfactual condition: if edible art is not regarded as food, our complete understanding of this kind of art is not possible.

First, the meaning of a revolutionary cooking dish comes through only if we experience the dish qua food rather than as performance art. Moreover, revolutionary cooking works in a way that highlights the multisensory character of the dining experience. The deconstruction of the dish is possible thanks to the expectations that are build based on the sense of sight. ${ }^{41}$ With our eyes we imagine the possible or desired flavour of the dish as well as judge its texture, patterns and overall plating. Only then can we actually feel surprised by the deconstructed form, combination of ingredients, or serving suggestion. After sampling the dish, we can relate the experience of taste and smell to other experiences and memories, and subsequently 'reconstruct' the dish as something that we are familiar with. For example, this is the case when the dish tastes familiar but looks unusual; e.g. traditional French onion soup in the form of a cube.

Second, failure to view revolutionary cooking dishes as set firmly in the context of food (thus, not experiencing and judging them primarily as food) can detract from and trivialise the viewing 
experience. A case in point is Piña colada (2004). Piña colada was served by Ferran Adrià in a cocktail glass. As it is poured into the glass (the waiter pours it from a considerable height), the stream turns into candy floss, which quickly evaporates. The glass is filled before all of the candy floss has evaporated. Here is what Jèssica Jacques and Gerard Vilar, Catalan philosophers, say about the dish: "Adrià's piña colada is presented to us as a clearly aesthetic sign, unlike the family soup; that is, as a symbol that questions the familiar modes of meaning, the ordinary intelligibility of things in the world. Thus, it does what art does; it offers us an alternative way of seeing that forces us to reflect and negotiate." 42 It should be emphasised that the comment refers to piña colada as a dish. Its aesthetic potential is generated precisely because we regard it as a culinary dish. Viewing it in purely decorative categories or as a kind of performance art detracts from the potentially interesting and extraordinary experience. After all, our experience is connected not only with the sheer physicality of the drink but also with a kind of 'embodied' idea that lies behind it. The idea is conveyed only when we view it as food-only then can we comprehend the innovative nature of the drink, i.e. after we have compared it with the familiar classic piña colada.

Third, viewing revolutionary cooking in terms of its products being first and foremost food (rather than, say, sculpture) makes us aware of its innovative and creative nature. Thanks to the strictly culinary experience that attaches to the dishes, we can fully appreciate the gastronomic dynamics and spot the changing trends in cooking and the multiplicity of ideas that underlie the making of a single dish. This last point is key, as it serves to restore the role of the cook and the activity of cooking to their proper place. This approach eventually leads to viewing gastronomy as not only a kind of practical skill but also an area where many cooks have made pioneering discoveries of taste and smell combinations.

Fourth, it is safe to say that the evolution of revolutionary cooking dishes assumes a different, theoretically wider, dimension because the cooking dishes are food. By this I mean a general rehabilitation of the senses of taste and smell as aesthetic senses. Traditional aesthetics derives its terminology mostly from experiences of sight and hearing. Potential appreciation of revolutionary cooking in terms reserved to art creates opportunities for the development of a new terminological paradigm that would adequately convey the experiences connected with the lower faculties. ${ }^{\mathbf{4 3}}$

Returning now to Korsmeyer's doubts about whether food can be a catalyst for reflection on the exquisiteness of food as food, 
we can counter by saying that revolutionary cooking sweeps those doubts aside quite successfully. As I have argued above, for them to be fully appreciated, revolutionary cooking dishes must be experienced primarily as food. The shock, admiration, or disgust that such dishes trigger says a lot not only about their unique taste combinations and about the underlying ideas, but also about our attitude to the world that surrounds us, our preferences, our emotions, and our open-mindedness. Reflection on revolutionary cooking dishes makes us wonder about the accuracy of another of Korsmeyer's claims whereby food in itself has no meaning except by reference to its context; e.g. some kind of cultural or social narrative. To rebut such claims, it is enough to say that many contemporary artworks are context dependent. Take for example the Brillo Box, which, according to Arthur Danto, takes on meaning and becomes art in the context of a certain artistic narrative. ${ }^{\mathbf{4 4}}$ As I have said, revolutionary cooking employs strategies similar to those of conceptual art: to understand revolutionary cooking dishes, we must have some knowledge about the history of culinary art (understood as a craft) and its principal paradigms. Most of these dishes challenge our conventional thinking about what makes food or how it should be eaten. As noted earlier, conceptual art plays similar tricks with other traditional forms of art. Revolutionary cooking cannot be 'people's art', as Telfer would have us believe. ${ }^{45}$ It requires an amount of information, attention, and experience comparable to that which accompanies the reception of other (higher) forms of art.

\section{CONCLUSION}

The aim of this paper has been to sketch the framework for experiencing, understanding and interpreting a new and emergent form of art, edible art. What I want to show is that if, in their theory of art, someone accepts the possibility of food being art, then there are no special reasons that food should not be regarded as high art. I have explained what it means for food to be an art that has also high manifestations (something I call 'edible art') and proposed that the necessary condition for this to be the case is that food should satisfy the Autonomy Condition. It says, roughly, that the artistic and aesthetic properties of food must come from perceiving food as food. In contemporary culinary trends, this condition is satisfied by revolutionary cooking. Revolutionary cooking shares some strategies with conceptual art, especially with regard to its revolutionary and revisionist nature. As I have shown, revolutionary cooking satisfies the Autonomy Condition because, 
to understand it completely, we must eat, experience and judge its dishes primarily as objects for consumption. Only then can their aesthetic, and possibly artistic, dimension be conveyed. Taking stock: if we assume that food can be art (as argued by Elisabeth Telfer and Carolyn Korsmeyer), then there is nothing to stop us from further claiming that certain forms of gastronomy can be regarded as high art. Revolutionary cooking is one such example.

\section{Acknowledgements}

For insightful comments and critical discussion, I owe thanks to Arto Haapala, Jèssica Jacques, Iwona Lorenc, Ossi Naukkarinen, Max Ryynänen, Mateusz Salwa, and Gerard Vilar. I am also indebted to an anonymous referee for many excellent suggestions as well as to the Editors of the NJA for good editorial experience. The work has been supported by the Foundation for Polish Science. 
1 Elisabeth Telfer, Food for Thought: Philosophy and Food (London: Routledge, 1996), 58-60.

2 Ibid., 59.

3 Carolyn Korsmeyer, Making Sense of Taste (Ithaca, NY: Cornell University Press, 1999).

4 Ibid., 141-145.

5 Ibid.,142.

6 See also Eileen John, 'Meals, Art, and Artistic Value', Estetika, LI/VII 2 2014, 254-268, at 258-259.

7 Ted Cohen 'High and Low Art, and High and Low Audiences', Journal of Aesthetics and Art Criticism 2 (57) 1999, 137-143.

8 For the sake of this argument, I assume that the distinction between 'high art' and 'minor art' is justified and it takes a form as described by Telfer and Korsmeyer. This is an unsettled issue, however. Cf. David Novitz, The Boundaries of Art (Philadelphia: Temple University Press, 1992).

9 David Davies, 'Medium in Art', in Jerrold Levinson, (ed.), Oxford Handbook of Aesthetics (Oxford: OUP, 2001), 181.

10 Timothy Binkley, 'Piece: Contra Aesthetics', Journal of Aesthetics and Art Criticism, 3 (35) 1977, 265-277, at 269-271.

11 Davies, 'Medium in Art', 188.

12 Dominic Mclver Lopes, 'Conceptual Art Is Not What It Seems', in Peter Goldie and Elisabeth Schellekens, (eds.), Philosophy and Conceptual Art (Oxford: OUP, 2007), 238-256, at 246-247.

13 Ibid., 247.

14 They are not the only faculties involved in experiencing food. It is worth noting the importance of sight or touch in the process of consumption. See more at § 4 .

15 Korsmeyer, Making Sense of Taste, 141.

16 Ibid., 142. Emphasis in the original.

17 Korsmeyer exercises caution in some places with regard to thinking of food in terms of art e.g. when claiming that the question whether food is art or not is not a crucial issue. She believes that in doing so, we might be tempted to ascribe more attributes to food than it actually has. Ibid., 144-145. I see her point but still a number of people (culinary bloggers, reviewers, chefs, gourmets as well as academics) keep asking about the artistic status of fine cuisine. Thus, I think this is an enough justification for giving a model of how we should understand this art form if we accept to agree that food may constitute artworks.

18 And for not confusing examples of edible art with e.g. sculptures made with a view to being eaten.

19 See e.g. Charles Spence, 'Multisensory flavour experience', Current Biology 9 (27) 2013, 365-369; Richard Stevenson, The Psychology of Flavour (Oxford: Oxford University Press, 2009).

20 Cf. Charles Michel, Carlos Velasco, Elia Gatti and Charles Spence, 'A taste of Kandinsky: assessing the influence of the artistic visual presentation of food on the dining experience', Flavour 3 (7) 2014, 1-10; Stephen Wooding, 'Olfaction: It Makes a World of Scents', Current Biology 16 (23) 2013, 677-679.

21 Recalling Kendall Walton, we can say that a work of art belongs to the category that yields its best quality and most uniform interpretation and experience. See his
'Categories of Art', The Philosophical Review, (3) 79 1970, 334-367, at 357.

22 One may still claim that it is not just the food that creates the aesthetic experience but rather the multimodal nature of dining. I agree that in many situations this is the case. However, such cases are not a subject of my considerations as explained by the Autonomy Condition.

23 Jèssica Jacques, 'Food', In Michael Kelly (ed.), Oxford Encyclopedia of Aesthetics, 2nd edition (Oxford: OUP, 2014), 63-67, at 64. For the purposes of this paper I accept that 'revolutionary cooking' covers such cooking styles as e.g. progressive cooking and deconstructionism.

24 Ferran Adrià, Heston Blumenthal, Thomas Keller, Harold McBee, 'Statement on the "New Cookery"', The Observer, 10th December 2006, accessed: 15.08.2016.

25 Erik van den Linden, David Julian McClements, Job Ubbink, 'Molecular Gastronomy: A Fad Food or an Interface for Science-based Cooking?', Food Biophysics, 2 (3) 2008, 246-254, at 247.

26 Juan-Carlos Arboleya, Idoia Olabarrieta, Andoni Luis-Aduriz, Daniel Lasa, Javier Vergara, Esther Sanmartin, Leire Iturriaga, Antonio Duch, Inigo Martinez de Maranon, 'From the Chef's Mind to the Dish: How Scientific Approaches Facilitate the Creative Process', Food Biophysics, 2 (3) 2008, 261-268.

27 Sol LeWitt, 'Paragraphs on Conceptual Art', Artforum, 5/10, 1976, 81.

28 Elisabeth Schellekens, 'Conceptual Art', Stanford Encyclopedia of Philosophy, 2007, accessed: 15.09.2016.

29 Peter Goldie, Elisabeth Schellekens, 'Introduction', in Idem., (eds.), Philosophy and Conceptual Art (Oxford: OUP, 2007), xii-xiii.

30 One could say that in the first case high art emerges from high art (conceptual art from traditional art) whereas in the second case high status of revolutionary gastronomy is, at least partly, explained by its reference to a low phenomenon - traditional gastronomy. In other words, one may wonder if it is possible for high art to emerge from a form of low art. This worry could be neutralised in two ways. First, it is possible to think of an art form that is originally associated with low art and then, through time, it develops the full aesthetic potential of its (both physical and artistic) medium. In such a case we end up with the art form of bilateral design which means that it has both high and low manifestations. An example is comics art. See Aaron Meskin, 'The Philosophy of Comics', Philosophy Compass 6/12, 2011, 854-864, at 855. Second, it is a sociological fact that over time in the process of 'legitimation' some art forms are gradually perceived as more valuable and liberated than they used to be. See Roberta Shapiro, Nathalie Heinich, 'When is Artification?', Contemporary Aesthetics, special issue 4, at §2.

31 The method itself is considered to be one of the indicators of creativity par excellence. See Silviya Svejenova, Carmelo Mazza, Marcel Planellas, 'Cooking Up Change in Haute Cuisine: Ferran Adrià as an Institutional Entrepreneur', Journal of Organizational Behavior, 5 (28) 2007, 539-561.

32 Ibid 
33 I would like to emphasise that there is no tension between this point and the role of culinary conventions in constituting an artistic medium as explained in $\S$ 2. Revolutionary cooking reflects on the classical conventions and helps us understand the medium violating it. On the other hand, the classical conventions are replaced by newly emerged ways of preparing, serving and experiencing dishes. I enumerate some of such techniques later on.

34 Synthesis of el Bulli cuisine, § 14, (elbulli.com), accessed: 10.08.2016.

35 Ibid., § 3.

36 Svejenova et al.

37 Ferran Adrià, Juli Soler, Albert Adrià, el Bulli 2003-4 (Ecco: Sant Adrià de Besòs, 2006), 111.

38 http://www.albertyferranadria.com/eng/texturas.html, accessed: 01.08.2017.

39 Jacques, 'Food', 64.

40 Arboleya et al., 267-268.

41 Cf. Jeannine F. Delwiche, 'You eat with your eyes first', Psychology \& Behavior 4 (107) 2012, 502-504; Charles Spence, Katsunori Okajima, Adrian David Cheok, Olivia Petit, Charles Michel, 'Eating with our eyes: From visual hunger to digital satiation', Brain and Cognition 110 (December) 2016, 53-63. One might realise the role of sight in creating gustatory expectations when visiting a restaurant offering a dinner without any source of light. An example of a restaurant providing such an experience is Dans Le Noir in London.

42 Jèssica Jacques, Gerard Vilar, 'Feeding Thought: A Philosophy of Cooking and Gastronomy', Disturbis, special issue 12 2012,1-28, at 21-22.

43 It is a distant goal, of course, but it is worth noting that attempts are being made to conceptualise this paradigm: it is called flavouring turn. See lbid., 11-28; Jacques, 'Food', 65-66.

44 Arthur Danto, 'Artworks and real things', Theoria, 1-3 (39) 1973, 1-17.

45 Cf. "Aesthetic eating, if I may call it this, is eating with attention and discernment food which repays attention and discernment. And to achieve attention and discernment may well take some practice and some instruction. On the other hand, the art of food is easier to appreciate than arts which require a lot of background information; the art of food is a possible people's art". Telfer, Food for Thought, 57. 